\title{
Pollination and breeding system of Canna paniculata (Cannaceae) in a montane Atlantic Rainforest: asymmetric dependence on a hermit hummingbird
}

\begin{abstract}
Pietro Kiyoshi Maruyama ${ }^{1,3,4}$, Jeferson Vizentin-Bugoni ${ }^{1}$, Bo Dalsgaard ${ }^{3}$ and Marlies Sazima ${ }^{2}$
Received: April 11, 2014. Accepted: July 9, 2014

ABSTRACT

We studied the pollination biology of Canna paniculata (Cannaceae), a plant species common in the Atlantic Rainforest of southeastern Brazil. The species presents specialized ornithophilous flowers, which in our study area are solely pollinated by the hermit hummingbird Phaethornis eurynome. Although C. paniculata is capable of bearing fruit after self-pollination, it requires pollinators for reproduction. We discuss the importance of hermit hummingbirds for the reproduction of specialized ornithophilous plants such as C. paniculata, including their asymmetric dependence on hermit hummingbirds - core pollinators in Neotropical forest ecosystems.
\end{abstract}

Keywords: hummingbirds, ornithophily, Phaethornis eurynome, Serra do Mar, Zingiberales

Hummingbirds arrived to South America some 22 million years ago (McGuire et al. 2014) and have since become the most important avian pollinator group in the Neotropics (Cronk \& Ojeda 2008). As a result of this strong mutualistic association between hummingbirds and plants, numerous plant groups have achieved remarkable diversity (e.g., Schmidt-Lebuhn et al. 2007). More comprehensive information on pollination and reproductive biology for plants belonging to some of these groups are now available, such as the study by Matallana et al. (2010) for Bromeliaceae. Zingiberales is another monocot plant clade in which bird pollination is common (Cronk \& Ojeda 2008), and although the pollination systems for some of the families within this group have been thoroughly studied (e.g., Costaceae, Kay \& Schemske 2003; Heliconiaceae, Stiles 1975; Zingiberaceae, Sakai et al. 1999) data are still lacking for other groups. Canna $\mathrm{L}$. is the only genus in Cannaceae and constitutes a conspicuous element in forests of the New World, where it is native, and in the Asian Paleotropics, where it has been introduced by humans (Prince 2010). The center of diversity of the family is South America (Prince 2010), and the species exhibit highly modified flowers, with the development of a colorful androecium and gynoecium with petaloid structures (Glinos \& Cocucci 2011). Through a process known as "secondary pollen presentation", the region below the apical and at the side of the lateral portion of the stigma acts as the pollen-dispensing structure, which demonstrates the unusual mechanism by which plants of the family achieve pollination (for details see Glinos \& Cocucci 2011). Nevertheless, besides the aforementioned study, which detailed the functional adaption of this unusual floral morphology for Canna indica L. (Glinos \& Cocucci 2011), we are unaware of other detailed studies on the pollination and reproduction for other species in the Canna family. Here, we report the pollination biology of Canna paniculata Ruiz \& Pav. from a montane Atlantic Rainforest area in southeastern Brazil. This species occurs in scattered localities at low to mid elevation $(<2,000 \mathrm{~m})$ throughout the wetter areas of the Neotropics, ranging from Panama in the north to southeastern Argentina (Prince 2010).

We studied C. paniculata at the Santa Virgínia Field Station ( $23^{\circ} 20^{\prime} 10^{\prime \prime} \mathrm{S}$ and $45^{\circ} 8^{\prime} 46^{\prime \prime} \mathrm{W}, 916-950 \mathrm{~m}$ above sea

\footnotetext{
${ }^{1}$ Pós-Graduação em Ecologia

${ }^{2}$ Departamento de Biologia Vegetal, Instituto de Biologia, Universidade Estadual de Campinas, (UNICAMP), Cx. Postal 6109, CEP: 13083-862, Campinas, SP, Brazil ${ }^{3}$ Center for Macroecology, Evolution and Climate, Natural History Museum of Denmark, University of Copenhagen, Universitetsparken 15, DK-2100 Copenhagen $\emptyset$, Denmark

${ }^{4}$ Corresponding author - pietrokiyoshi@gmail.com
} 
level), located in Serra do Mar State Park in the state of São Paulo, Brazil, where C. paniculata is particularly common. Fieldwork was conducted during the flowering season of C. paniculata (June-September) in 2012 and 2013. Flowers were accompanied during the anthesis and collected for morphological measurements $(\mathrm{n}=10$, one for each individual). Individuals were defined as clumps at least 5 $\mathrm{m}$ apart as the plant presents clonal growing. For all floral measurements, we used a digital caliper (error $=0.01 \mathrm{~mm}$ ). In order to characterize the breeding system of C. paniculata, we conducted controlled pollination experiments with the following treatments: 1) manual "cross-pollination" (crossing between flowers from different individuals); 2) manual "self-pollination" (pollination within the same flower); 3 ) "spontaneous self-pollination" (flowers kept isolated in nylon mesh bags); 4) "agamospermy" (flowers emasculated before opening and kept isolated); and 5) marked control flowers open to visitation to estimate "natural pollination". All treatments were distributed as much as possible among 22 individuals within the study area, and only flowers at the first day of opening were used in the treatments. The fruit set was evaluated two months after the experiments. In order to quantify the volume of nectar produced and its concentration at the end of the day ( 17:00), flowers were bagged before opening with nylon mesh bags and nectar was measured using a microsyringe and a pocket refractometer (Eclipse ${ }^{\circledR} 0-50$ brix; $\mathrm{n}=17$ flowers from 12 individuals). We also conducted 60 hours of plant focal observations in eight individuals from 06:00 to 18:00 to identify the pollinators of C. paniculata.

C. paniculata presents red-orange flowers with traces of yellow (Fig. 1A) and individual clumps offer $4.3 \pm 3.9$ (range of 1-20) flowers per day during the flowering period. The opening of flowers started early in the morning

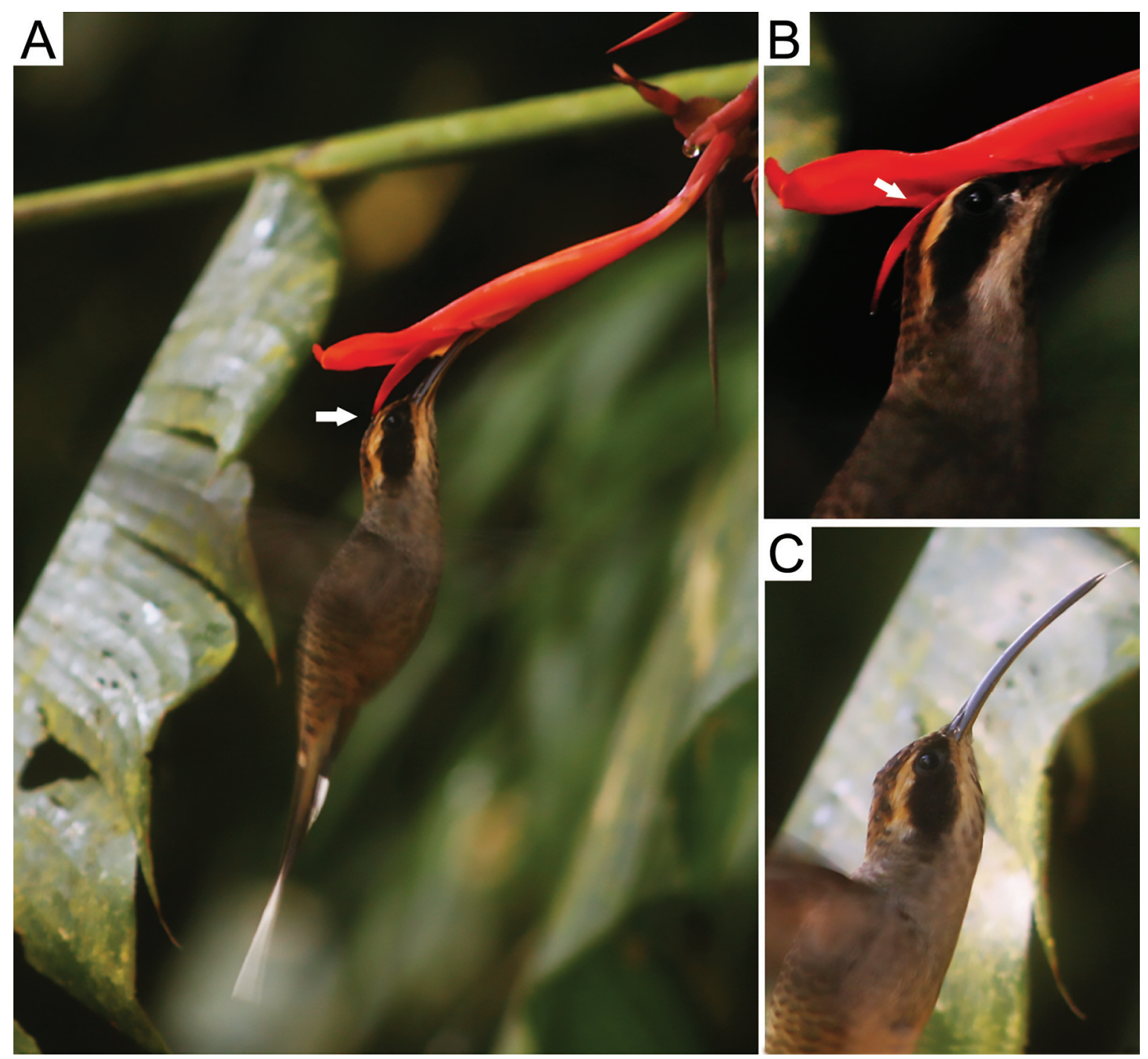

Figure 1. A, Phaethornis eurynome (Lesson 1832), visiting the flower of Canna paniculata Ruiz \& Pav. Note the head of hummingbird contacting the apical receptive part of the stigma (arrow) when approaching the flower. B, When the bill is completely inserted in the corolla, the hummingbird's head makes contact with the flattened part of the style (arrow), which acts as secondary pollen presenter. C, In detail, the long and curved bill of $P$. eurynome. 
before sunrise $(\sim 06: 00)$ and lasted until the afternoon of the second day $(\sim 16: 00)$, i.e., flowers lasted roughly $1 \frac{1 / 2}{2}$ days. As reported for other members of the family (Glinos \& Cocucci 2011), C. paniculata showed secondary pollen deposition at the side of the flattened style, where pollen is deposited by the single theca in an elliptical clump. Flowers measure $c a .6 \mathrm{~cm}$ in total length, but the actual restriction to the pollinator, i.e., the corolla tube, amounts to $4.07 \pm 1.03$ $\mathrm{cm}$ in length with $0.51 \pm 0.12 \mathrm{~cm}$ of opening. Controlled pollination experiments showed that $C$. paniculata is able to produce fruits after self-pollination, although the fruit set is less than half in comparison to cross-pollinated flowers (Table 1). Moreover, this species requires pollinators to bear seeds, as no fruit was set after spontaneous self-pollination or agamospermy. Flowers exposed to natural pollination had two times more fruit set than self-pollinated flowers, but $13.8 \%$ less than cross-pollinated flowers (Table 1). Nectar production amounted to $45.0 \pm 34.5 \mu \mathrm{l}$, with sugar concentration of $23.4 \% \pm 3.11 \%$. During focal observations, the only pollinator observed was the Scale-throated hermit, Phaethornis eurynome (Lesson 1832), which visited individuals of $C$. paniculata 84 times (1.40 \pm 0.94 visits/hour). This species seemingly acted as a "trapliner", returning at the same clump of flowers at roughly regular intervals (see Stiles 1975). When approaching the flower, the hummingbird first touched the tip of the stigma (i.e., the receptive region, see Fig. 1A, marked with an arrow) with its head, and subsequently, the clump of pollen deposited in the flattened style was pressed against the head of the pollinator (Fig. 1B, marked with an arrow). During our fieldwork, we also noted that stingless bees, Trigona sp., robbed nectar from approximately $20.8 \%(n=250)$ of flowers.

Despite being a widespread group in the tropics, this is only the second detailed report on pollination and breeding biology for a Canna species. Hummingbird pollination seems to be common for species in the genus, but presumably the one species occurring in North America, C. flaccida Salisb., is pollinated by nocturnal moths (Prince 2010). C. indica is also pollinated by a single species of hummingbird in Argentina, the Blue-tufted starthroat, Heliomaster furcifer (Shaw 1812), from the Mountain gems clade (Glinos \& Cocucci 2011). The prevalence of hummingbird pollination (or other birds in introduced areas) in Cannaceae requires

Table 1. Fruit set after controlled pollination experiments and natural pollination in Canna paniculata Ruiz \& Pav. (Cannaceae) at the Santa Virgínia Field Station, Serra do Mar State Park, São Paulo, Brazil.

\begin{tabular}{lc}
\hline Pollination treatment & $\%$ (Flowers) \\
\hline Cross-pollination & $53.8(\mathrm{n}=52)$ \\
Self-pollination & $19.2(\mathrm{n}=52)$ \\
Spontaneous self-pollination & $0.0(\mathrm{n}=65)$ \\
Agamospermy & $0.0(\mathrm{n}=58)$ \\
Natural pollination & $40.0(\mathrm{n}=70)$ \\
\hline
\end{tabular}

further investigation. The identity of C. paniculata's sole pollinator and external morphological characteristics of the flowers conform to the classical notion of ornithophily, and this is reinforced by the presence of abundant and diluted nectar similar to other ornithophilous species (Cronk \& Ojeda 2008). Moreover, bird pollination in other groups within Zingiberales resembles the adaptations found in $C$. paniculata. For instance, in Costus L. (Costaceae), adaptation to hummingbird pollination is achieved by narrow, long tubular flowers with brightly colored bracts (yellow, orange, or red), which present copious amount of nectar (Kay \& Schemske 2003). Similar traits are found for hummingbird pollinated Heliconiaceae in wet forests of Costa Rica (Stiles 1975). In the Bornean Zingiberaceae, sunbirdpollinated species also presented long tubular corollas with conspicuous colors (often red), and with copious production of more diluted nectar in relation to insect pollinated species (Sakai et al. 1999). Altogether, these parallels reinforce the association of some prominent floral traits to specialized bird pollination within Zingiberales.

Although both C. indica and C. paniculata have similarly elongated corolla flowers, differences in pollinating hummingbird species imply distinct areas of pollen deposition. For a non-hermit species, $H$. furcifer has a long bill of 2.8 $\pm 0.2 \mathrm{~cm}$ in length, enabling it to access the nectar in the flower. However, because its bill is straight (Glinos \& Cocucci 2011), during its visits the bill is tightly encased in the slightly curved floral tube, and pollen is deposited on the hummingbird's bill when it forces its way out of this "entrapment" (Glinos \& Cocucci 2011). In C. paniculata, pollination is carried out by the hermit $P$. eurynome with a curved bill of $3.4 \pm 0.1 \mathrm{~cm}$ (Vizentin-Bugoni et al. 2014; Fig. 1C), which promotes a good fit to the long, slightly curved corolla of the flower. While visiting the flower, the head of the hummingbird often touches the receptive part of the stigma first, and thereafter it comes into contact with the pollen (Fig. 1A, C). Although this does not ensure crosspollination, since an individual plant can present more than one open flower at a time, chances of self-pollination are at least diminished.

Considering the breeding system, C. paniculata can be regarded as self-compatible (with an Index of SelfIncompatibility of 0.36 -estimated as the division of the fruit set through self-pollination by cross-pollination, as in Wolowski et al. 2013), similar to other groups of monocots strongly associated to hummingbird pollination such as the bromeliads (Matallana et al. 2010) and hummingbird pollinated plants in general (Wolowski et al. 2013). Nevertheless, C. paniculata requires pollinators to set fruits, characterizing its dependence on pollen vectors. Naturally pollinated (i.e., control) flowers show P. eurynome as a relatively good pollinator, being able to set more fruits than when self-pollinated, even though pollination success is not as high as hand crosspollination. The distinctive traplining behavior of hermit hummingbirds, as we may also infer for P. eurynome, is 
expected to increase the rates of outcrossing (Stiles 1975), which also characterizes hermit hummingbirds as relatively efficient pollinators. This is further supported if one considers that for C. indica pollinated by $H$. furcifer, a presumably territorial hummingbird, fruit set in control flowers was only $20 \%$ in comparison to $86 \%$ in hand crossed flowers (Glinos \& Cocucci 2011). These results illustrate the link between distinct hummingbird behaviors (e.g., territorialism) and pollination success (Justino et al. 2012).

At the community level, in the studied montane Atlantic Rainforest site, P. eurynome is a "core" hummingbird pollinator, interacting with more plant species than any other hummingbird species, and being the sole pollinator of many long-tubed flowers; at least 24 other plant species, 15 of which have overlapping flowering with C. paniculata (Vizentin-Bugoni et al. 2014). Similar community organization is found in lowland Atlantic Forest areas, where the Saw-billed hermit Ramphodon naevius (Dumont 1818) is solely responsible for the pollination of the more specialized long-tubed flowers (Sazima et al. 1995). Also in the Neotropical savanna, where patches of forest habitats are found embedded in the landscape, similar organization can be seen, where the Planalto hermit P. pretrei (Lesson \& Delattre 1839) interact with the more specialized flowers (Maruyama et al. 2014). In summary, this suggests that there is an asymmetrical interaction between hermit hummingbirds and the plant species they pollinate. While many plant species (such as C. paniculata) depend on only one hermit hummingbird species for their reproduction, each plant species alone potentially has less importance for the hermit hummingbirds that pollinate them. Although this asymmetry between interacting plants and hummingbirds might vary among communities (see Maruyama et al. 2013), it should have strong implications for the structure and dynamics of the entire plant-hummingbird community, and hence, deserves further investigations.

\section{Acknowledgments}

We thank the staff and administration of the Santa Virgínia Field Station for approving our study, as well as $\mathrm{CNPq}$ and Capes for financial support. We also thank two anonymous reviewers for comments which improved our manuscript. This study was founded by $\mathrm{CNPq}$ and
CAPES (processo: 99999.012341/2013-04). PKM, JV-B and BD thank the Danish National Research Foundation for its support of the Center for Macroecology, Evolution, and Climate.

\section{References}

Cronk Q, Ojeda I. 2008. Bird-pollinated flowers in an evolutionary and molecular context. Journal of Experimental Botany 59: 715-727.

Glinos E, Cocucci AA. 2011. Pollination biology of Canna indica (Cannaceae) with particular reference to the functional morphology of the style. Plant Systematics and Evolution 291:49-58

Justino DG, Maruyama PK, Oliveira PE. 2012. Floral resource availability and hummingbird territorial behaviour on a Neotropical savanna shrub. Journal of Ornithology 153: 189-197.

Kay KM, Schemske DW. 2003. Pollinator assemblages and visitation rates for 11 species of Neotropical Costus (Costaceae). Biotropica 35: 198-207.

Maruyama PK, Oliveira GM, Ferreira C, Dalsgaard B, Oliveira PE. 2013. Pollination syndromes ignored: importance of non-ornithophilous flowers to Neotropical savanna hummingbirds. Naturwissenschaften 100: 1061-1068.

Maruyama PK, Vizentin-Bugoni J, Oliveira GM, Oliveira PE, Dalsgaard B. 2014. Morphological and spatio-temporal mismatches shape a Neotropical savanna plant-hummingbird network. Biotropica 46: 740-747.

Matallana G, Godinho MAS, Guilherme FAG, Belisario M, Coser TS, Wendt T. 2010. Breeding systems of Bromeliaceae species: evolution of selfing in the context of sympatric occurrence. Plant Systematics and Evolution 289: 57-67.

McGuire JA, Witt CC, Remsen Jr JV, et al. 2014. Molecular phylogenetics and the diversification of hummingbirds. Current Biology 24: 910-916.

Prince LM. 2010. Phylogenetic relationships and species delimitation in Canna (Cannaceae). In: Seberg O, Petersen G, Barfod AS, Davis J. (eds.) Diversity, phylogeny, and evolution in the monocotyledons. Aarhus, Aarhus University Press. p. 307-331.

Sakai S, Kato M, Inoue T. 1999. Three pollination guilds and variation in floral characteristics of Bornean gingers (Zingiberaceae and Costaceae). American Journal of Botany 86: 646-658.

Sazima I, Buzato S, Sazima M. 1995. The saw-billed hermit Ramphodon naevius and its flowers in southeastern Brazil. Journal of Ornithology 136: 195-206.

Schmidt-Lebuhn AN, Kessler M, Hensen I. 2007. Hummingbirds as drivers of plant speciation? Trends in Plant Science 12: 329-331.

Stiles FG. 1975. Ecology, flowering phenology, and hummingbird pollination of some Costa Rican Heliconia species. Ecology 56: 285-301.

Vizentin-Bugoni J, Maruyama PK, Sazima M. 2014. Processes entangling interactions in communities: forbidden links are more important than abundance in a hummingbird-plant network. Proceedings of the Royal Society B: Biological Sciences 281: 20132397.

Wolowski M, Saad CF, Ashman TL, Freitas L. 2013. Predominance of selfcompatibility in hummingbird-pollinated plants in the Neotropics. Naturwissenschaften 100: 69-79. 